\title{
Nedaplatin sensitization of cisplatin-resistant human non-small cell lung cancer cells
}

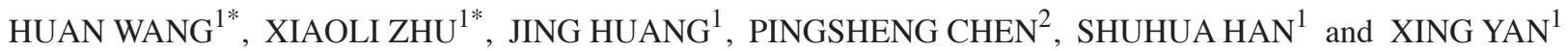 \\ ${ }^{1}$ Department of Respiratory Medicine, The Affiliated Zhongda Hospital of Southeast University; \\ ${ }^{2}$ Department of Pathology, Medical School of Southeast University, Nanjing, Jiangsu 210009, P.R. China
}

Received January 5, 2015; Accepted February 4, 2016

DOI: $10.3892 / \mathrm{ol} .2016 .4276$

\begin{abstract}
Cisplatin (DDP) has been one of the most widely used chemotherapy drugs for advanced non-small cell lung cancer. However, the increase in the number of DDP-resistant cancer cells has become a major impediment in the clinical management of cancer. In the present study, for the first time, the 3-(4,5-dimethylthiazol-2yl)-2,5-diphenyltetrazolium bromide assay was used to demonstrate that nedaplatin (NDP) could have a stronger inhibitory effect than DDP alone in DDP-resistant A549 (A549DDP) cells and that it could attenuate the resistance of these cells. Additionally, flow cytometry analysis showed that the apoptosis rate of these resistant cells when exposed to NDP was markedly increased and the number of cells in the G2 stage of the cell cycle was significantly increased. Furthermore, western blot analysis indicated that NDP decreased the protein expression of P-glycoprotein, tumor protein p53 and B-cell lymphoma 2, and increased the expression of Bcl-2-associated $\mathrm{X}$ protein, all of which could possibly improve the NDP intracellular drug concentration and promote cell apoptosis. These observations suggested that NDP could have higher efficacy in DDP-resistant lung cancer cells, and further studies applying more detailed analyses are warranted to elucidate the mechanism(s) behind this effect.
\end{abstract}

\section{Introduction}

Lung cancer is the leading cause of cancer-associated mortality worldwide, and $\sim 85 \%$ of lung cancer diagnoses are of non-small cell lung cancer (NSCLC) $(1,2)$. Although great progress has been made in small molecular-targeted drugs for treating NSCLC, particularly epidermal growth factor receptor (EGFR) tyrosine kinase inhibitors such as gefitinib and erlotinib, EGFR

Correspondence to: Professor Xiaoli Zhu, Department of Respi ratory Medicine, The Affiliated Zhongda Hospital of Southeast University, Medical School of Southeast University, 87 Dingjiaqiao Road, Gulou, Nanjing, Jiangsu 210009, P.R. China

E-mail: zhuxiaoliseu@sina.com

*Contributed equally

Key words: non-small cell lung cancer, resistance, cisplatin, nedaplatin mutations are detected in only $10 \%$ of NSCLC patients in the United States and in 35\% of NSCLC patients in East Asia. Thus, platinum-based combination chemotherapies remain the mainstay of advanced NSCLC treatment, and cisplatin (DDP) is widely used in clinical therapy (3). However, the overall 5-year survival rate for lung cancer is $\sim 15 \%$, and this rate has improved only slightly over the last 30 years despite the advancement of modern chemotherapy, a problem which is mainly caused by drug resistance to platinum (4).

The problem of resistance to DDP-based chemotherapy remains one of the major obstacles to the treatment of lung cancer. A number of mechanisms have been proposed to explain cancer cell resistance to chemotherapy $(5,6)$. These mechanisms generally involve an increase in the level of multidrug resistance-1/P-glycoprotein (P-gp) $(7,8)$, and the regulation of apoptosis-related genes and proteins such as tumor protein p53 (p53) and B-cell lymphoma 2 (Bcl-2) family members (9-11). However the underlying mechanisms are not yet fully understood. Thus, there is an urgent requirement to learn how to improve the efficacy of platinum or to identify a novel generation of platinum agents.

Nedaplatin (NDP), which is a second-generation DDP analog, was developed by the Shionogi Pharmaceutical Company (Japan) in 1983, in order to provide a treatment with a level of effectiveness similar to that of DDP, but with decreased gastrointestinal and renal toxicities (12). A number of previous clinical studies have demonstrated the efficacy of NDP to be higher than that of DDP in patients with DDP-resistant lung cancer $(13,14)$. Conversely, there are comparatively few in vitro studies to support the consensus. Moreover, it is unclear why NDP is not completely cross-resistant with DDP.

The purpose of the present study was to demonstrate the efficacy of NDP in DDP-resistant A549 (A549DDP) cells in vitro directly. Moreover, the study aimed to detect the expression of DDP resistance-related proteins, such as P-gp, p53, Bcl-2-associated $\mathrm{X}$ protein (Bax) and $\mathrm{Bcl}-2$, to investigate the possible mechanisms behind NDP efficacy in the A549DDP cells.

\section{Materials and methods}

Cell culture. The human NSCLC A549 cell line and the human DDP-resistant cell strain, A549DDP, were used in this study. The cells were obtained from Shanghai Cell Biology, an Institute of the Chinese Academy of Sciences (Shanghai, China). 
The A549 cell line was cultured in RPMI-1640 medium supplemented with $100 \mathrm{U} / \mathrm{ml}$ penicillin, $100 \mathrm{mg} / \mathrm{ml}$ streptomycin and $10 \%$ fetal bovine serum (Invitrogen; Thermo Fisher Scientific, Inc., Waltham, MA, USA). The A549DDP cells were cultured in high glucose Dulbecco's modified Eagle's medium supplemented with $100 \mathrm{U} / \mathrm{ml}$ penicillin, $100 \mathrm{mg} / \mathrm{ml}$ streptomycin and $10 \%$ fetal bovine serum; $2 \mu \mathrm{g} / \mathrm{ml}$ DDP (Jiangsu Haosen Pharmaceutical Co., Ltd., Lianyungang, China) was dissolved into this solution in order to maintain drug resistance. However, the A549DDP cells were grown in the absence of DDP 2 days prior to treatment. These cells were incubated in a standard cell culture incubator (Series 8000 Water-Jacketed $\mathrm{CO}_{2}$ Incubator; Thermo Fisher Scientific, Inc.) at $37^{\circ} \mathrm{C}$ with $5 \% \mathrm{CO}_{2}$, and passaged once or twice a week. Cells in the algorithm growth phase were used in the following experiments.

Cell proliferation and the 3-(4,5-dimethylthiazol-2yl)-2,5-diphenyltetrazolium bromide (MTT) assay. The half maximal inhibitory concentration $\left(\mathrm{IC}_{50}\right)$ of the A549DDP and A549 cells was determined by the MTT assay (Beyotime, Shanghai, China). The A549 and A549DDP cells were seeded into 96-well plates $\left(1 \times 10^{4}-1 \times 10^{5}\right.$ cells per well), and treated with DDP and NDP (Jiangsu Aosaikang, Nanjing, China) at different concentrations (A549 cells: 2, 4, 6, 8 and $10 \mu \mathrm{g} / \mathrm{ml}$; A549DDP cells: $10,15,20,25$ and $30 \mu \mathrm{g} / \mathrm{ml}$ ) for $48 \mathrm{~h}$. Following incubation, $5 \mathrm{mg} / \mathrm{ml} \mathrm{MTT} \mathrm{(20} \mu \mathrm{l} /$ well) was added to the media and the cells were further incubated in an atmosphere of $5 \% \mathrm{CO}_{2}$ at $37^{\circ} \mathrm{C}$ for $4 \mathrm{~h}$. Dimethylsulfoxide (150 $\mu \mathrm{l}$; Sigma-Aldrich, St. Louis, MO, USA) was added to the cells in each of the wells after the media was removed, and the cells were further incubated for $10 \mathrm{~min}$. The optical density (OD) of each well was measured using a microplate reader (Multiskan ${ }^{\mathrm{TM}}$ GO Microplate Spectrophotometer; Thermo Fisher Scientific, Inc.) at $560 \mathrm{~nm}$. All experiments were performed in triplicate according to the following formula: Cell inhibitory rate $(\%)=(1-$ OD of test group / OD of control group) x 100 .

Apoptosis detection and cell cycle analysis. The rate of apoptosis induced by the anticancer regimens was analyzed by flow cytometry using an annexin V-fluorescein isothiocyanate/propidium iodide kit (Kaijibio, Nanjing, China). Adherent and floating cells were harvested and gently disaggregated to a single-cell suspension. Staining was performed according to the manufacturer's protocols. The data were analyzed immediately by flow cytometry using CXP software (Beckman Coulter, Inc., Brea, CA, USA).

Protein isolation and western blot analysis. Subsequent to exposure to DDP and NDP for $48 \mathrm{~h}$, cell protein extracts were determined using $500 \mu \mathrm{l}$ radioimmunoprecipitation assay lysis buffer with $5 \mu \mathrm{l}$ phenylmethylsulfonyl fluoride and protease inhibitor (Abcam,Cambridge,UK). Total proteins were quantified using the bicinchoninic acid assay (Beyotime, Shanghai, China) according to the manufacturer's protocols. Total protein $(20 \mu \mathrm{g})$ was loaded onto an $8 \%$ sodium dodecyl sulfate-polyacrylamide gel and transferred to a polyvinylidene difluoride membrane (EMD Millipore, Billerica, MA, USA). The membrane was incubated for $1 \mathrm{~h}$ at $25^{\circ} \mathrm{C}$ in $5 \%(\mathrm{w} / \mathrm{v})$ skimmed dried milk and then washed three times for $5 \mathrm{~min}$ at $25^{\circ} \mathrm{C}$ using blocking buffer [Tris-buffered saline with Tween 20 (TBST) buffer: $0.1 \%$ Tween

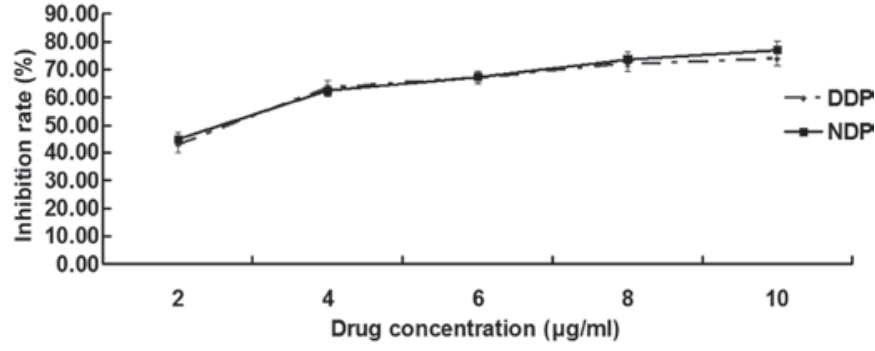

Figure 1.3-(4,5-dimethylthiazol-2yl)-2,5-diphenyltetrazolium bromide assay detection of the inhibition of A549 cell proliferation after $48 \mathrm{~h}$ of intervention with cisplatin (DDP) and nedaplatin (NDP) at different concentrations.

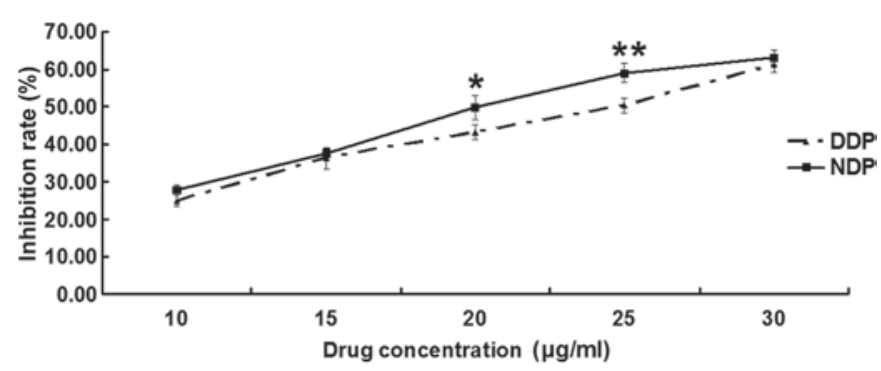

Figure 2. 3-(4,5-dimethylthiazol-2yl)-2,5-diphenyltetrazolium bromide assay detection of the inhibition of A549DDP cell proliferation after $48 \mathrm{~h}$ of intervention with cisplatin (DDP) and nedaplatin (NDP) at different concentrations. Compared with DDP, NDP could significantly inhibit A549DDP cells proliferation $\left({ }^{*} \mathrm{P}<0.05,{ }^{* *} \mathrm{P}<0.01\right)$

20, $13.7 \mathrm{mM} \mathrm{NaCl}, 0.27 \mathrm{mM} \mathrm{KCl}$ and $2.4 \mathrm{mM}$ Tris). Next, the membrane was incubated overnight at $4^{\circ} \mathrm{C}$ with monoclonal mouse anti-human primary antibodies for P-gp (clone, JSB-1; catalog no., ab3366), p53 (clone, PAb 1801; catalog no., ab28), Bax (clone, 2D2; catalog no., ab77566) and Bcl-2 (clone, Bcl2/100; catalog no., ab117115). All antibodies were diluted to 1:1,000 and purchased from Abcam. Subsequent to being washed three times with TBST for $5 \mathrm{~min}$ each, the membranes were incubated for $1 \mathrm{~h}$ with horseradish peroxidase-conjugated secondary antibodies (goat anti-rabbit IgG; 1:5,000; catalog no., sc-2004; Santa Cruz Biotechnology Inc., Dallas, TX, USA). In order to evaluate of protein expression accurately, $\beta$-actin (mouse monoclonal; clone, AC-15; catalog no., ab6276; Abcam) and histone $\mathrm{H} 3$ protein (mouse monoclonal; clone, mAbcam 1220; catalog no., ab1220; Abcam) were used as an internal standard. Band intensity was analyzed with an imaging and analysis system (Peiqing JS-780; Hai Pei Qing Technology Co., Ltd., Shanghai, China), and protein expression was presented as the ratio of the protein band intensity to $\beta$-actin or Histone $\mathrm{H} 3$ in the same blot.

Statistical analysis. The values presented represent the mean \pm standard deviation calculated from the data. All analyses were performed using the Statistical Package for Social Sciences, version 13 (SPSS Inc., Chicago, IL, USA). Differences were evaluated using Student's t-test or an analysis of variance.

\section{Results}

Cell inhibitory measurement by MTT assay. An MTT assay was used to determine the sensitivity of A549DDP cells to DDP, to investigate whether these cells are resistant to DDP 
Table I. Inhibition A549 cells after $48 \mathrm{~h}$ of intervention with DDP and NDP at different concentrations.

\begin{tabular}{lcccccc}
\hline & \multicolumn{5}{c}{ Drug concentration, $\mu \mathrm{g} / \mathrm{ml}$} \\
\cline { 2 - 6 } Group & 2 & 4 & 6 & 8 & 10 & $\mathrm{IC}_{50}$ \\
\hline DDP & $42.78 \pm 2.50$ & $63.21 \pm 2.73$ & $66.79 \pm 1.76$ & $72.06 \pm 2.83$ & $73.68 \pm 2.51$ & $2.53 \pm 0.12$ \\
NDP & $44.84 \pm 2.32$ & $62.34 \pm 1.97$ & $67.28 \pm 1.96$ & $73.56 \pm 2.63$ & $76.88 \pm 3.04$ & $2.49 \pm 0.78$ \\
P-value & 0.354 & 0.677 & 0.765 & 0.537 & 0.232 & 0.834 \\
\hline
\end{tabular}

DDP, cisplatin; NDP, nedaplatin; $\mathrm{IC}_{50}$, half maximal inhibitory concentration.

Table II. Inhibition of A549DDP cells after $48 \mathrm{~h}$ of intervention with DDP and NDP at different concentrations.

\begin{tabular}{lcccccc}
\hline & \multicolumn{5}{c}{ Drug concentration, $\mu \mathrm{g} / \mathrm{ml}$} \\
\cline { 2 - 6 } Group & 10 & 15 & 20 & 25 & 30 & $\mathrm{IC}_{50}$ \\
\hline DDP & $24.79 \pm 1.53$ & $36.28 \pm 2.85$ & $43.25 \pm 2.04$ & $50.38 \pm 1.95$ & $60.54 \pm 1.66$ & $23.36 \pm 1.41$ \\
NDP & $27.74 \pm 1.48$ & $39.20 \pm 2.91$ & $49.93 \pm 3.22$ & $59.05 \pm 2.56$ & $63.21 \pm 1.93$ & $19.97 \pm 0.88$ \\
P-value & 0.074 & 0.283 & $0.038^{\mathrm{a}}$ & $0.009^{\mathrm{a}}$ & 0.144 & $0.024^{\mathrm{a}}$ \\
\hline
\end{tabular}

${ }^{\mathrm{a}} \mathrm{P}<0.05$. DDP, cisplatin; NDP, nedaplatin; $\mathrm{IC}_{50}$, half maximal inhibitory concentration .

Table III. Cell apoptosis rate induced by DDP and NDP, as detected by flow cytometry.

\begin{tabular}{lcrrr}
\hline Group & Q1 & Q2 & Q3 & Q4 \\
\hline Control, \% & $3.49 \pm 1.74$ & $2.60 \pm 0.47$ & $92.78 \pm 1.69$ & $1.11 \pm 0.17$ \\
DDP, \% & $4.09 \pm 3.35$ & $3.63 \pm 2.06$ & $83.81 \pm 5.55$ & $8.47 \pm 1.54$ \\
NDP, \% & $9.64 \pm 3.75$ & $11.80 \pm 1.50$ & $60.97 \pm 6.70$ & $17.59 \pm 2.81$ \\
\hline
\end{tabular}

Q1 represents necrotic cells, Q2 represents late apoptotic cells, Q3 represents living cells and Q4 represents early apoptotic cells. DDP, cisplatin; NDP, nedaplatin.

Table IV. Detection of DDP- and NDP-induced cell cycle arrest by flow cytometry.

\begin{tabular}{lccc}
\hline Group & G1 & $\mathrm{S}$ & $\mathrm{G} 2$ \\
\hline Control, \% & $68.04 \pm 3.50$ & $15.81 \pm 3.04$ & $14.44 \pm 2.59$ \\
DDP, \% & $54.53 \pm 5.84$ & $19.73 \pm 6.93$ & $25.73 \pm 5.84$ \\
NDP, \% & $51.52 \pm 8.59$ & $17.34 \pm 5.39$ & $31.47 \pm 4.76$ \\
\hline
\end{tabular}

DDP, cisplatin; NDP, nedaplatin.

and to determine whether NDP has a stronger inhibitory effect than DDP in A549DDP cells.

The inhibition rate is shown in Figs. 1 and 2, and Tables I and II. For the first part of the MTT assay, the $\mathrm{IC}_{50}$ values of the A549 and A549DDP cells treated with DDP were $2.53 \pm 0.12$ and $23.36 \pm 1.41 \mu \mathrm{g} / \mathrm{ml}$, respectively, and the difference between them was significant $(\mathrm{P}<0.001)$, which verified that A549DDP cells exhibit resistance to DDP.
In the second part, of the MTT assay, the $\mathrm{IC}_{50}$ of the A549 cells treated with DDP and NDP was $2.53 \pm 0.12$ and $2.49 \pm 0.78 \mu \mathrm{g} / \mathrm{ml}$, respectively (Fig. 1; Table I), and the difference was not significant $(\mathrm{P}=0.834)$. However, the $\mathrm{IC}_{50}$ values of the A549DDP cells treated with DDP and NDP were $23.36 \pm 1.41$ and $19.97 \pm 0.88 \mu \mathrm{g} / \mathrm{ml}$ (Fig. 2; Table II); this difference was significant, suggesting that NDP had a better effect than DDP on the A549DDP cells.

Cell apoptosis and the cell cycle, as shown by flow cytometry. Flow cytometry was used to investigate the differences in cell apoptosis and the cell cycle between the A549DDP cells treated with DDP and NDP. After $48 \mathrm{~h}$ of intervention with DDP $(20 \mu \mathrm{g} / \mathrm{ml})$ and NDP $(20 \mu \mathrm{g} / \mathrm{ml})$, the levels of cell apoptosis in the NDP and DDP groups increased and were significant when compared with the control group (each $\mathrm{P}<0.01$ ). In comparison with the DDP group, the degree of early and late apoptosis in the NDP group increased, and this difference was significant ( $\mathrm{P}=0.010$ and $\mathrm{P}=0.005$, respectively) (Fig. 3; Table III).

In comparison with the control group, the percentage of cells in $\mathrm{G} 2$ increased $(\mathrm{P}=0.021$ and $\mathrm{P}=0.005$, respectively) and 
A
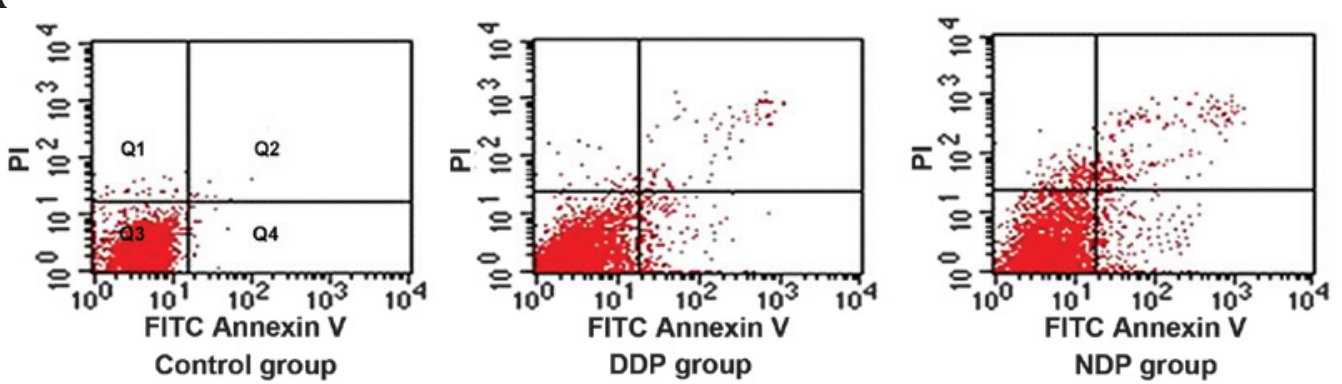

$\mathbf{B}$

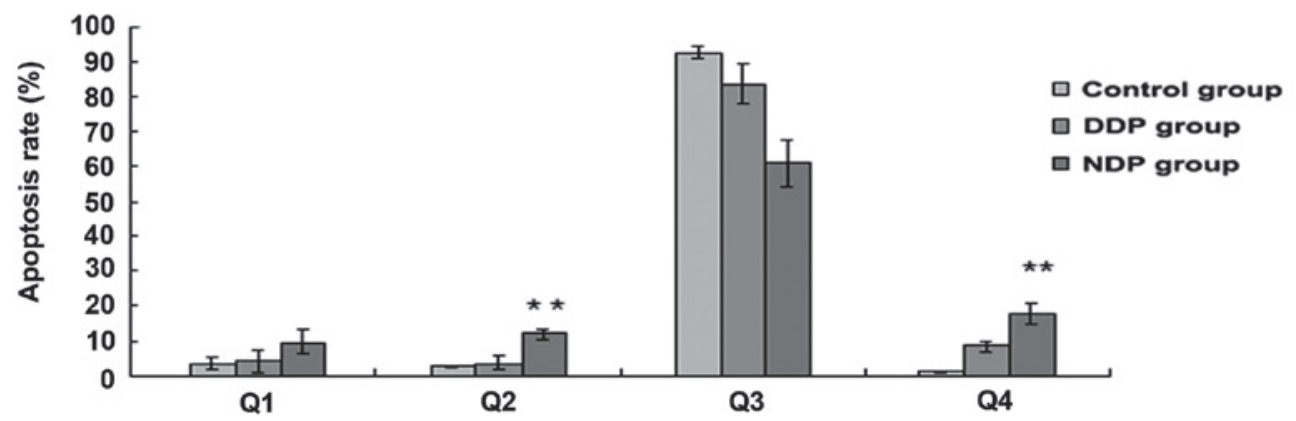

Figure 3. Cell apoptosis, as detected by flow cytometry. (A) Cell apoptosis was examined using flow cytometry. (B) Quantification was used to show the difference of cell apoptosis in the NDP group compared with the control and DDP group. ${ }^{* *}$ Compared with the control and DDP groups, the NDP group exhibited a higher rate of apoptosis ( $\mathrm{P}<0.01)$. Q1, necrotic cells; Q2, apoptotic cells; Q3, living cells; Q4, early apoptotic cells; FITC, fluorescein isothiocyanate; DDP, cisplatin; NDP, nedaplatin
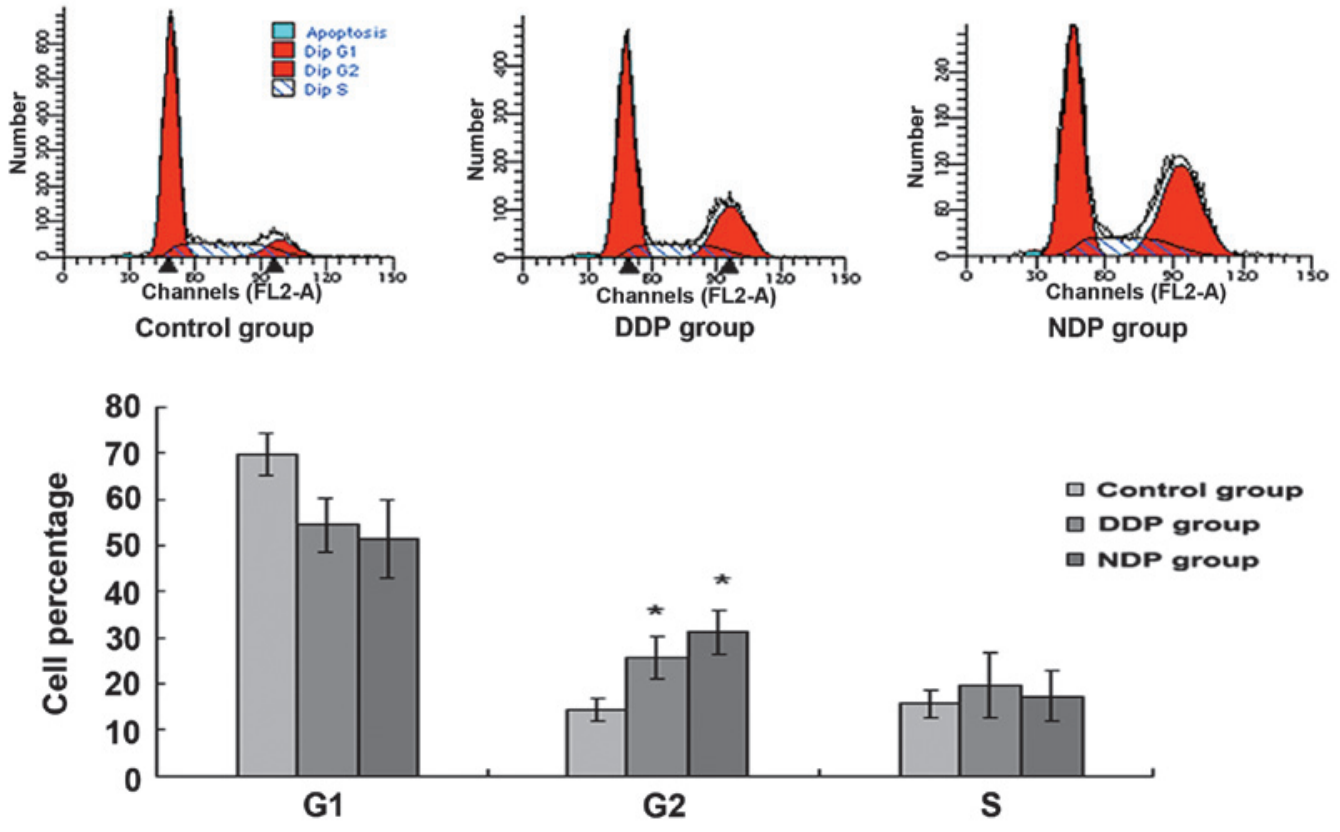

Figure 4. Cell cycle arrest induced by DDP and NDP, as detected by flow cytometry. ${ }^{*}$ Compared with the control group, the DDP and NDP groups exhibited higher percentages of A549DDP cells in the $\mathrm{G} 2$ phase $(\mathrm{P}<0.05)$. However the difference between the DDP and NDP groups was not significant. DDP, cisplatin; NDP, nedaplatin.

the proportion in the $\mathrm{G} 1$ stage decreased $(\mathrm{P}=0.023$ and $\mathrm{P}=0.031$, respectively) following intervention with DDP and NDP, and the difference was significant (Fig. 4; Table IV). Furthermore the difference in the percentage of cells in the G2 phase between the DDP and NDP groups was not significant $(\mathrm{P}=0.228)$.

Protein expression and western blot analysis. Western blotting results revealed that the expression levels of P-gp, p53,
Bax and Bcl-2 in the NDP group were different from the levels of expression in the control and DDP groups.

P-gp relative expression in the NDP group was $0.50 \pm 0.03$, which was significantly higher than that of the control $(0.80 \pm 0.12 ; \mathrm{P}=0.015)$ and $\mathrm{DDP}(0.63 \pm 0.05 ; \mathrm{P}=0.014)$ groups (Fig. 5). However, compared with the control group, the expression of P-gp in the DDP group was not significantly different $(\mathrm{P}=0.094)$. 
A

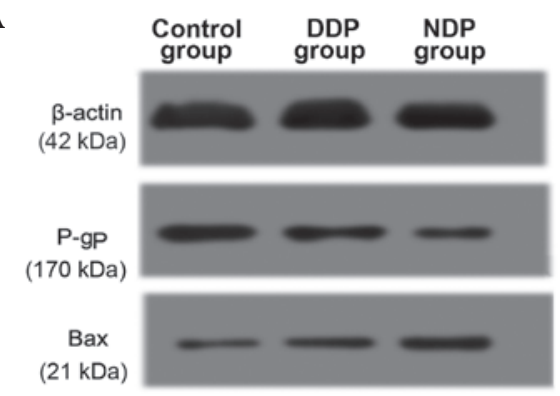

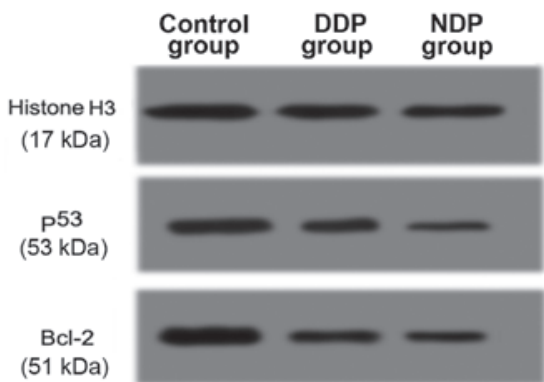

$(51 \mathrm{kDa})$
B

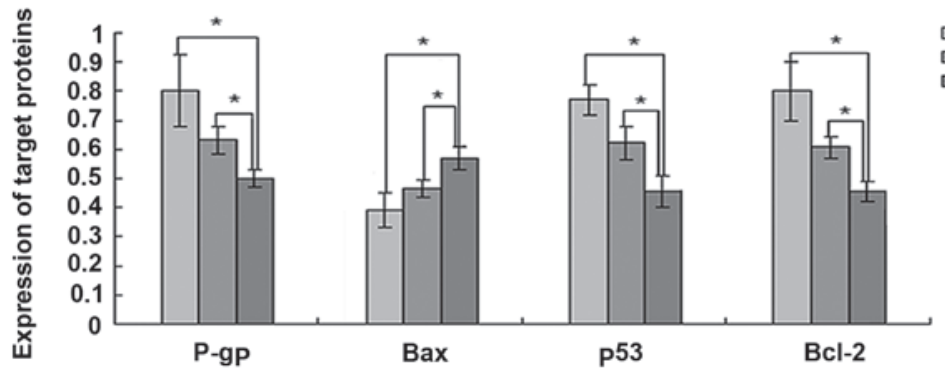

$\square$ Control group

$\square$ DDP group

NDP group

Figure 5. Expression of P-gp, p53, Bcl-2 and Bax in the three groups, as detected by western blot assay. (A) Protein expression was examined using western blotting and recorded with a scanner system. (B) The relative expression of target proteins (compared with $\beta$-actin protein or histone H3 protein expression) in the three groups. "Compared with the control or DDP groups, the NDP group exhibited significantly lower or higher expression of the target poteins $(\mathrm{P}<0.05)$. DDP, cisplatin; NDP, nedaplatin; P-gp, P-glycoprotein; p53, tumor protein 53; Bcl-2, B-cell lymphoma 2; Bax, Bcl-2-associated X protein.

The relative expression levels of 553 in the control, DDP and NDP groups were $0.77 \pm 0.05,0.62 \pm 0.06$ and $0.45 \pm 0.05$, respectively. p53 expression in the NDP and DDP groups was significantly less than in the control group ( $\mathrm{P}=0.002$ and $\mathrm{P}=0.020$, respectively) (Fig. 5). Compared with the DDP group, the NDP group exhibited a lower p53 expression level, and the difference was significant $(\mathrm{P}=0.020)$.

The relative expression of Bax in the NDP group was $0.57 \pm 0.04$, which was significantly higher than that of the control $(0.39 \pm 0.06 ; \mathrm{P}=0.012)$ and DDP $(0.46 \pm 0.03 ; \mathrm{P}=0.024)$ groups (Fig. 5). By contrast, the Bax expression in the DDP group, when compared to the control group, did not exhibit a significant difference $(\mathrm{P}=0.112)$.

However, the western blot analysis revealed that the relative expression of Bcl-2 in the control, DDP and groups was $0.80 \pm 0.10,0.60 \pm 0.04$ and $0.45 \pm 0.04$, respectively. Bcl-2 expression in the NDP and DDP groups was significantly lower than that in the control group $(\mathrm{P}=0.005$ and $\mathrm{P}=0.005$, respectively) (Fig. 5). Compared with the DDP group, the NDP group exhibited lower Bcl-2 expression, and the difference was also significant $(\mathrm{P}=0.008)$.

\section{Discussion}

The present study results showed that at the same concentration, NDP had a higher cell inhibition rate than DDP in A549DDP cells, particularly for concentrations of 20 and $25 \mu \mathrm{g} / \mathrm{ml}(\mathrm{P}=0.038$ and $\mathrm{P}=0.009$, respectively). It was also found that the blockage of the cell cycle at the G2 phase in the A549DDP cells increased significantly following intervention with DDP and NDP, but that the difference between these two groups was not significant. However, compared with the DDP group, the NDP group exhibited significantly greater early and late apoptosis ratios. Therefore, it was concluded that the use of NDP was more advantageous than the use of DDP in A549DDP cells. In this study, the results also showed that the expression levels of P-gp, p53 and Bcl-2 in the NDP group were significantly less than those of the other two groups, and that the expression of Bax in the NDP group was significantly higher. Moreover it was found that the difference in Bcl-2 expression between the NDP and DDP groups was more pronounced $(\mathrm{P}=0.008)$.

$\mathrm{P}-\mathrm{gp}$ is one of the major drug efflux transporters; it increases the efflux of drugs out of cells against the concentration gradient, thereby reducing the intracellular concentration of the drug below the effective level, which finally leads to drug resistance $(8,15)$. It has been verified that a number of anticancer drugs, including DDP, etoposide and vinblastine, are P-gp substrates (16). The results of the present study showed that the P-gp expression level of cells exposed to NDP was significantly lower than that of cells exposed to DDP. Thus, it was concluded that NDP could possibly inhibit the P-gp expression level, thereby decreasing the efflux of drugs out of the A549DDP cells. This would improve the NDP intracellular drug concentration, which would suppress A549DDP cell proliferation.

Lung cancer cells have been shown to possess a higher p53 mutation rate (70\%); the mutation of the gene could result in abnormal expression of the 553 protein (17). The wild-type p53 protein is able to exert a range of anti-proliferative effects, including the induction of apoptosis and causing a marked increase in the sensitivity of these cells to DDP $(18,19)$. However malignancies with mutated p53 genes and aberrant p53 proteins in laboratory studies and one clinical study have been observed to be less responsive to chemotherapy agents that induce DNA damage, such as DDP $(20,21)$. A number of studies have suggested that the overexpression of the mutant p53 protein may directly enhance tumor cell resistance to 
anticancer agents in a way that is dependent on the particular mutation and the mechanism of action of the drug (22-24). In a situation of cellular stress, such as DNA damage, the mutated p53 genes and aberrant p53 proteins participate in the process of inducing cell-cycle arrest, and can enhance DNA repair or cell death and upregulate the expression of P-gp $(25,26)$. In the present study, compared with DDP intervention, NDP intervention led to a significant downregulation of $\mathrm{p} 53$ protein. Combined with the greater downregulation of P-gp protein following NDP intervention, this results indicates that the mutant p53 protein was likely detected in the A549DDP cells, and that NDP could inhibit the expression of the mutant p53 protein, thereby decreasing the upregulation of P-gp expression in order to withstand DDP resistance.

There are numerous members in the Bcl-2 family, and while certain members, such as Bcl-2, are anti-apoptotic, other, such as Bax, are pro-apoptotic. The ratio between pro- and anti-apoptotic Bcl-2 family members is a significant determinant of cell survival and cell death. A number of cancer chemotherapeutic agents ultimately act on these factors causing cells to undergo apoptosis (27). The Bcl-2 family plays a significant role in the cellular response to chemotherapy. The overexpression of $\mathrm{Bcl}-2$ increases the resistance to drug-induced apoptosis, and the survival of Bcl-2-negative tumors is less than that of Bcl-2-positive tumors $(28,29)$. In the present study, it was found that the Bcl-2 expression level of NDP-exposed cells was significantly lower than that in cells exposed to DDP, while the Bax expression level in the NDP-exposed cells was significantly greater. It was concluded that NDP could regulate Bcl-2 and Bax expression, thereby promoting the apoptosis of A549DDP cells by allowing NDP to withstand DDP resistance.

Clinically, an association has been observed between NDP and an improved response in DDP-resistant cancer (13,30,31). Therefore, in the present study, the effect of NDP on A549DDP cells was analyzed by in vitro experimentation, which has not yet been verified in any previous findings. Eventually, this may assist in providing important clues to guide clinicians towards better therapy decisions. However, the present study has the certain limitations. Firstly, the study failed to demonstrate the further mechanism(s) of the effect of NDP on A549DDP cells. Secondly, these findings should be extended to other resistant cell lines and animal experiments. Finally, the collection and systematic evaluation of extensive clinical data should be performed in order to confirm the in vivo relevance of the findings.

In summary, the present study suggested that NDP could have higher efficacy in DDP-resistant lung cancer cells and that its effect may be multifactorial. Compared with DDP, NDP was able to decrease the P-gp and p53 protein expression levels to improve the NDP intracellular drug concentration, and could regulate the expression of Bcl-2 family members to promote apoptosis. Further studies applying more detailed analyses are warranted to elucidate the mechanism(s) of the effect of NDP on DDP-resistant lung cancer cells.

\section{References}

1. Ferlay J, Shin HR, Bray F, Forman D, Mathers C and Parkin DM: Estimates of worldwide burden of cancer in 2008: GLOBOCAN 2008. Int J Cancer 127: 2893-2917, 2010.
2. Azzoli CG, Temin S and Giaccone G: 2011 Focused update of 2009 American society of clinical oncology clinical practice guideline update on chemotherapy for stage IV non-small-cell lung cancer. J Oncol Pract 8: 63-66, 2012.

3. Ettinger DS, Akerley W, Borqhaei H, Chang AC, Cheney RT, Chirieac LR, D'Amico TA, Demmy TL, Govindan R, Grannis FW Jr, et al: Non-small cell lung cancer, version 2.2013. J Natl Compr Canc Netw 11: 645-653, 2013.

4. Rigas JR: Taxane-platinum combinations in advanced non-small cell lung cancer: A review. Oncologist 9 (Suppl 2): S16-S23, 2004.

5. Davis A, Tinker AV and Friedlander M: 'Platinum resistant' ovarian cancer: What is it, who to treat and how to measure benefit? Gynecol Oncol 133: 624-631, 2014.

6. Torigoe T, Izumi H, Ishiguchi $\mathrm{H}$, et al: Cisplatin resistance and transcription factors. Curr Med Chem Anticancer Agents 5: 15-27, 2005.

7. Gao L, Liu G, Ma J, Wang X, Wang F, Wang H and Sun J: Paclitaxel nanosuspension coated with P-gp inhibitory surfactants: II. Ability to reverse the drug-resistance of H460 human lung cancer cells. Colloids Surf B Biointerfaces 117: 122-127, 2014.

8. Yamagishi T, Sahni S, Sharp DM, Arvind A, Jansson PJ and Richardson DR: P-glycoprotein mediates drug resistance via a novel mechanism involving lysosomal sequestration. J Biol Chem 288: 31761-31771, 2013.

9. Cavallo F, Feldman DR and Barchi M: Revisiting DNA damage repair, p53-mediated apoptosis and cisplatin sensitivity in germ cell tumors. Int J Dev Biol 57: 273-280, 2013.

10. Yang M, Shan X, Zhou X, Qiu T, Zhu W, Ding Y, Shu Y and Liu P: miR-1271 regulates cisplatin resistance of human gastric cancer cell lines by targeting IGF1R, IRS1, mTOR and BCL2. Anticancer Agents Med Chem 14: 884-891, 2014.

11. Wang G, Reed E and Li QQ: Molecular basis of cellular response to cisplatin chemotherapy in non-small cell lung cancer (Review). Oncol Rep 12: 955-965, 2004.

12. Ota K: Nedaplatin. Gan To Kagaku Ryoho 23: 379-387, 1996 (In Japanese).

13. Jin J, Xu X, Wang F, Yan G, Liu J, Lu W, Li X, Tucker SJ, Zhong B, Cao $\mathrm{Z}$ and Wang D: Second-line combination chemotherapy with docetaxel and nedaplatin for cisplatin-pretreated refractory metastatic/recurrent esophageal squamous cell carcinoma. J Thorac Oncol 4: 1017-1021, 2009.

14. Li CH, Liu MY, Liu W, Li DD and Cai L: Randomized control study of nedaplatin or cisplatin concomitant with other chemotherapy in the treatment of advanced non-small cell lung cancer. Asian Pac J Cancer Prev 15: 731-736, 2014.

15. Sharom FJ: Complex interplay between the P-glycoprotein multidrug efflux pump and the membrane: Its role in modulating protein function. Front Oncol 4: 41, 2014.

16. Fu D: Where is it and how does it get There-intracellular localization and traffic of P-glycoprotein. Front Oncol 3: 321, 2013.

17. Vaughan CA, Singh S, Windle B, Yeudall WA, Frum R, Grossman SR, Deb SP and Deb S: Gain-of-function activity of mutant p53 in lung cancer through up-regulation of receptor protein tyrosine kinase axl. Genes Cancer 3: 491-502, 2012.

18. Wu ZZ, Sun NK and Chao CC: Knockdown of CITED2 using short-hairpin RNA sensitizes cancer cells to cisplatin through stabilization of p53 and enhancement of p53-dependent apoptosis. J Cell Physiol 226: 2415-2428, 2011.

19. Bazzi $\mathrm{H}$ and Anderson KV: Acentriolar mitosis activates a p53-dependent apoptosis pathway in the mouse embryo. Proc Natl Acad Sci USA 111: E1491-E1500, 2014.

20. Oren M and Rotter V: Mutant p53 gain-of-function in cancer. Cold Spring Harb Perspect Biol 2: a001107, 2010.

21. Perrone F, Bossi P, Cortelazzi B, Locati L, Quattrone P, Pierotti MA, Pilotti S and Licitra L: TP53 mutations and pathologic complete response to neoadjuvant cisplatin and fluorouracil chemotherapy in resected oral cavity squamous cell carcinoma. J Clin Oncol 28: 761-766, 2010.

22. Bossi G, Lapi E, Strano S, Rinaldo C, Blandino G and Sacchi A: Mutant p53 gain of function: Reduction of tumor malignancy of human cancer cell lines through abrogation of mutant p53 expression. Oncogene 25: 304-309, 2006.

23. Tian B, Liu J, Liu B, Dong Y, Liu J, Song Y and Sun Z: p53 Suppresses lung resistance-related protein expression through Y-box binding protein 1 in the MCF-7 breast tumor cell line. J Cell Physiol 226: 3433-3441, 2011.

24. Cuddihy AR, Jalali F, Coackley C and Bristow RG: WTp53 induction does not override MTp53 chemoresistance and radioresistance due to gain-of-function in lung cancer cells. Mol Cancer Ther 7: 980-992, 2008 
25. Chung SK, Zhu S, Xu Y and Fu X: Functional analysis of the acetylation of human p53 in DNA damage responses. Protein Cell 5: 544-551, 2014.

26. Podolski-Renić A,Jadranin M,StankovićT, Banković J, StojkovićS, Chiourea M, Aljančić I, Vajs V, Tešević V, Ruždijić S, et al: Molecular and cytogenetic changes in multi-drug resistant cancer cells and their influence on new compounds testing. Cancer Chemother Pharmacol 72: 683-697, 2013.

27. Pore MM, Hiltermann TJ and Kruyt FA: Targeting apoptosis pathways in lung cancer. Cancer Lett 332: 359-368, 2013.

28. Kumar Biswas S, Huang J, Persaud S and Basu A: Down-regulation of $\mathrm{Bcl}-2$ is associated with cisplatin resistance in human small cell lung cancer H69 cells. Mol Cancer Ther 3 : 327-334, 2004.

29. Gumulec J, Balvan J, Sztalmachova M, Raudenska M, Dvorakova V, Knopfova L, Polanska H, Hudcova K, Ruttkay-Nedecky B, Babula P, et al: Cisplatin-resistant prostate cancer model: Differences in antioxidant system, apoptosis and cell cycle. Int J Oncol 44: 923-933, 2014.
30. Akutsu Y, Shuto K, Kono T, Uesato M, Hoshino I, Shiratori T, Miyazawa Y, Isozaki Y, Akanuma N and Matsubara H: A phase 1/11 study of second-line chemotherapy with fractionated docetaxel and nedaplatin for 5-FU/cisplatin-resistant esophageal squamous cell carcinoma. Hepatogastroenterology 59: 2095-2098, 2012.

31. Yoshioka T, Sakayori M, Kato S, Chiba N, Miyazaki S, Nemoto K, Shibata H, Shimodaira H, Ohtsuka K, Kakudo Y, et al: Dose escalation study of docetaxel and nedaplatin in patients with relapsed or refractory squamous cell carcinoma of the esophagus pretreated using cisplatin, 5-fluorouracil and radiation. Int J Clin Oncol 11: 454-460, 2006. 